\title{
Travel medicine for divers
}

\author{
Krzysztof Korzeniewski ${ }^{1}$, Jarosław Krzyżak ${ }^{2}$ \\ ${ }^{1}$ Department of Epidemiology and Tropical Medicine, Military Institute of Medicine, Warsaw, Poland \\ ${ }^{2}$ Polish Society of Hyperbaric Medicine and Technique, Gdynia, Poland
}

\begin{abstract}
Recreational diving is increasing in popularity globally, also among European travellers. Since a majority of popular diving sites are located in tropical or subtropical destinations commonly characterised by harsh climate and poor sanitation, travellers planning to engage in recreational diving are recommended to take certain health prevention measures to reduce travel-associated health risks. They need to be aware of the fact that diving can threaten their lives or even be fatal; however, if they are well prepared physically and mentally and follow all the recommended safety rules while underwater, diving is an unforgettable experience that cannot be compared to any other sports activity performed on land. Before going on a diving trip, it is important to make the necessary arrangements, bearing in mind they should not only concentrate on diving-related activities (the marine environment) but also on other aspects, e.g. contact with terrestrial flora and fauna. Therefore, the health prevention measures (a pre-travel consultation, vaccinations, antimalarial chemoprophylaxis, a properly prepared travel health kit and travel insurance) are to keep a traveller healthy during the entire travel and not just the moments of going underwater. The most important of the pre-travel arrangements include pre-travel medical evaluation, selecting and preparing medications for chronic conditions and assembling the first aid kit for personal use. Travellers are recommended to have a pre-travel consultation in medical facilities whose personnel have an appropriate level of knowledge and expertise on hyperbaric, tropical and travel medicine.
\end{abstract}

(Int Marit Health 2017; 68, 4: 215-228)

Key words: divers, travel medicine, prophylaxis

\section{VISIT TO A HEALTH CARE PROVIDER}

During a pre-travel consultation a doctor will assess the health status of a traveller and determine whether he has any contraindications to diving. All travellers planning to go on a diving trip, especially for the first time, should undergo a detailed assessment, including the examination of the respiratory, cardiovascular and auditory systems, paranasal sinuses and the patient's mental condition [1]. The past medical history of a traveller is also important; particular attention should be paid to the following: respiratory system illnesses (bronchial asthma), illnesses which can cause loss of consciousness (diabetes, epilepsy), mental disorders (anxiety), cardiovascular diseases (arterial hypertension, coronary heart disease) [2]. Travellers diving regularly should undergo such a physical examination periodically. The World Recreational Scuba Training Council (www.wrstc.com) has introduced the physical examination guidelines for deter- mining fitness or absolute contraindications to diving. The guidelines have been approved by the Divers Alert Network (www.diveralertnetwork.org) and the Undersea and Hyperbaric Medicine Society (www.membership.uhms.org) [3].

During the medical evaluation of divers, or candidates for divers, their age and sex need to be taken into account. Divers $>50$ years of age need to be fully aware of their limited fitness and abilities as well as contraindications to diving associated with the presence of chronic conditions or the regular intake of medications. Although there are no formal age restrictions, the minimum age for recreational diving is 12 years, on condition that the child is physically and mentally fit for diving (enough physical strength to carry scuba equipment, emotional maturity) and has no contraindications to diving (e.g. the Eustachian tube dysfunction). Apart from pregnancy, there are no specific contraindications to diving for women. Women are recom- 
Table 1. Selected medications and their possible adverse effects on divers. Source: [2]

\begin{tabular}{ll}
\hline Medications & Note \\
\hline Narcotic/analgesic & Narcotic - contraindicated; NSAIDs - no contraindications \\
Cardiac & Some hypotension medications can reduce exercise tolerance \\
Insulin & Blood glucose concentration should be checked before each dive \\
Antidepressant & Contraindicated \\
Anticonvulsant & Contraindicated \\
Antimalarial & Mefloquine - contraindicated; doxycycline, atovaquone/proguanil - no contraindications \\
Sympathomimetics & Pseudoephedrine can reduce the risk of pressure-related ear injury \\
Anti-motion sickness & Cause sedation, impair the activity of central nervous system \\
\hline NSAIDs - non-steroidal anti-inflammatory drugs
\end{tabular}

NSAIDs - non-steroidal anti-inflammatory drugs

mended to avoid diving during menstruation if it triggers migraine headaches [1].

A large proportion of recreational divers are treated for chronic conditions or receive medications (e.g. antimalarial chemoprophylaxis) which have no effect on diving. Yet, it needs to be remembered that some medications are contraindicated for divers (Table 1). Individuals planning to go diving who have just started a new drug regimen should report any adverse effects that have occurred to their health care provider so that the medication can be changed before travel [4-6].

According to the Divers Alert Network, cardiovascular diseases are the second most common cause of fatalities among divers [7]. Therefore, special attention needs to be given to cardiological patients during the medical assessment of divers or candidates for divers. Mild-to-moderate asthma with normal spirometry should not be considered an absolute contraindication to diving [8]. According to the guidelines for medical assessment of divers, diabetic patients must receive a fixed-dose insulin therapy for at least 12 months or oral antidiabetic agents for at least 3 months before a dive, the glycated haemoglobin level should be $\leq 9 \%$, and there should be no episodes of hyperglycaemia or hypoglycaemia for 12 months before diving [9].

The aim of a pre-travel consultation is to discuss diving-related issues, but in order that a doctor could recommend appropriate prevention measures, a patient must also be ready to talk about the following: the itinerary (country, part of the world, height above sea level, climate, sanitary conditions), the length of stay, departure and return dates, the type of accommodation (a hotel, a low-cost hostel), types of activities they are going to undertake (a beach holiday, scuba diving, mountain climbing, jungle or desert expeditions, cave exploration), vaccinations received (primary, complementary or booster doses), the use of antimalarials, allergies to food products, cosmetics, medications or egg white protein (ingredient of vaccines), chronic or ongoing conditions, currently taken medications, carriage of infectious diseases, immunodeficiency, pregnancy [10-12].

Diving-related morbidity is not much different from morbidity rates associated with other forms of physical activity. The estimated incidence of decompression sickness is 5-80 cases per 100,000 dives [13]. The risk of death among the American and European Divers Alert Network is estimated at $1 / 6,000$ dives per year. In comparison, the risk of jogging-related death is $1 / 7,700$ joggers per year [14]. Officially, drowning is the most common cause of death among divers; however, the biggest challenge for medical professionals dealing with undersea medicine are problems associated with the supply of air/air mixtures, a too fast ascent or the presence of conditions which are contraindications to diving $[7,14]$.

\section{MANDATORY AND RECOMMENDED VACCINATIONS}

According to the World Health Organisation (WHO) guidelines, international travellers are required to receive vaccinations against two infectious diseases: invasive meningococcal disease and yellow fever. The former is compulsory for Muslim pilgrims to Saudi Arabia, while the latter is mandatory for travellers to disease endemic countries (30 countries in Africa and 13 in Central and South America) (Table 2), as well as for short term-travellers to the above-mentioned countries (even if it is a $12 \mathrm{~h}$ transit) further travelling to one of the 90 countries listed by the WHO (interestingly, vaccination is not compulsory in Chile and Uruguay - the only South American countries free from the yellow fever transmission, but is mandatory for travellers to Albania and Malta, i.e. European countries which is free from transmission) [15].

\section{YELLOW FEVER}

Yellow fever is an especially dangerous, infectious disease caused by a virus of the Flaviviridae family. The infection is transmitted through a bite from an infected 
Table 2. Epidemiology of yellow fever

\begin{tabular}{|c|c|}
\hline Continents & Countries \\
\hline Africa & $\begin{array}{l}\text { Angola, Benin, Burkina Faso, Burundi, Cameroon, Central African Republic, Congo, Chad, Ivory Coast, } \\
\text { Democratic Republic of Congo, Equatorial Guinea, Ethiopia, Gabon, Gambia, Ghana, Guinea, } \\
\text { Guinea-Bissau, Kenya, Liberia, Mali, Mauritania, Niger, Nigeria, Senegal, Sierra Leone, Somalia, Sudan, } \\
\text { South Sudan, Togo, Uganda }\end{array}$ \\
\hline Central and South America & $\begin{array}{l}\text { Argentina, Bolivia, Brazil, Ecuador, Guiana, French Guiana, Colombia, Panama, Paraguay, Peru, Suriname, } \\
\text { Trinidad and Tobago, Venezuela }\end{array}$ \\
\hline
\end{tabular}

mosquito of the Aedes, Haemagogus or Sabethes genus. The disease is often asymptomatic; however, in severe cases the infection can be fatal. Typical signs and symptoms include: fever, headaches, chills, nausea, fatigue, jaundice and a red eye. Some patients exhibit severe complications including liver or renal failure as well as gastrointestinal bleeding (haemorrhagic fever).

The risk for travellers. The risk of contracting yellow fever is 10 times higher in Africa than in South America. In western parts of Africa, the disease is most commonly transmitted during the late wet season and the early dry season (July-October). In South America, the virus is most commonly found in Brazil and Peru (the risk of transmission is particularly high during the wet season lasting from January until March). The estimated risk of acquiring a severe, potentially fatal, form of yellow fever during a 2-week trip to endemic areas for an unvaccinated traveller is 1:2,000-1: 10,000 in Africa and 1:20,000 - 1: 100,000 in Central and South America [16].

Prevention. Vaccination is the best way to prevent yellow fever (95\% of vaccinated individuals confer immunity against the yellow fever virus). In many countries the vaccination against yellow fever is mandatory and foreign visitors are required to present The International Certificate of Vaccination before they can enter the country. A live attenuated vaccine containing 17 DAKAR strain of the yellow fever virus is available in Poland (Stamaril). According to the resolution WHA67.13 adopted by the World Health Assembly on $11^{\text {th }}$ July 2016 booster doses against yellow fever are no longer required and a single dose of the vaccine is sufficient to confer lifetime immunity against the disease. The vaccine should be taken at least 10 days before travel into endemic areas. The vaccine is contraindicated in patients allergic to egg white or other vaccine components, children below 6 months, patients with congenital, inherited or acquired immunodeficiency (e.g. caused by immunosuppressive treatment), patients with thymus dysfunction, HIV patients with $\mathrm{CD} 4^{+}$lymphocyte count $<200 / \mu \mathrm{L}$. Special precautions need to be taken in children aged 6-8 months, patients $>60$ years of age, pregnant or breastfeeding women, HIV patients with $\mathrm{CD}^{+}$ lymphocyte count < 200-499/ $\mathrm{L}[15,17]$.

\section{INVASIVE MENINGOCOCCAL DISEASE}

Invasive meningococcal disease is caused by the Neisseria meningitidis bacteria (mainly serogroups $A, B$ and $C$, less commonly $Y$ and $W-135)$. The infection can present as the invasive meningococcal disease most commonly manifesting with meningitis or sepsis. The disease is spread by droplet transmission, direct or indirect physical contact with an infected individual or his secretions. The most common clinical signs include sudden paroxysmal fever, headaches, neck stiffness, nausea, vomiting, and haemorrhagic rash. The disease may have a particularly severe course and lead to central nervous system (CNS) damage, multiple organ failure, coagulation disorders and eventually death.

Epidemiology. Neisseria meningitidis is a cosmopolitan pathogen. Carriage rates have been estimated to range between $5 \%$ to $10 \%$ worldwide. Outbreaks of the disease are primarily reported from areas with large concentrations of people (Muslim pilgrimages to Saudi Arabia) and from closed environments (military units, prisons, hostels). The disease is frequently found in the Sahel, i.e. the countries lying between Senegal and Ethiopia, (the so-called 'meningitis belt'), mostly during the dry season lasting from November to June.

Risk for travellers. Travelers to Sub-Saharan Africa, to the Sahel region are at the highest risk for developing meningococcal infection. The risk increases if a traveller maintains close contact with the local community or stays in densely populated areas [17].

Prevention. Vaccination against meningococcal disease is recommended for all travellers to endemic areas. The best choice for international travellers is a conjugated tetravalent meningococcal vaccine against serogroups A,C,Y,W-135. It is administered in a single dose (Menveo, Nimenrix); according to the manufacturer, booster doses are not required. The vaccine ought to be administered at least 2 weeks before departure into endemic areas. Vaccination against the meningococcal disease is mandatory for all travellers to Saudi Arabia going on a pilgrimage to Mecca (travellers are required to present a Certificate of Vaccination documenting the doses of the tetravalent A, C, W-135, Y vaccine they have received). Travelers to Saudi Arabia other than pilgrims are not legally required to receive vaccination against meningo- 
coccal disease (unlike the yellow fever vaccine). However, the vaccine is strongly recommended and can improve health security of travellers to endemic areas. Generally, vaccines need to be taken 4- 6 weeks before travel so that there is enough time to receive all the required doses and confer immunity. Yet, even if it is less than 4 weeks before departure, travellers are recommended to consult with a health care provider in order to obtain the information on the possibility of receiving single doses of a vaccine or taking an accelerated vaccination course. Travelers who received a primary course of vaccinations against infectious diseases in the past are recommended to receive boosters before departure [17-20].

\section{POLIOMYELITIS}

Poliomyelitis (the Heine-Medin disease, infantile paralysis) is an acute contagious disease caused by the Poliovirus (serotype 1, 2, 3). Currently, only infections with Poliovirus type 1 and 2 are being reported (type 3 poliovirus was last seen in 2012 in Nigeria). The disease is transmitted through a direct physical contact with an infected person or a carrier, or contact with their excrement and throat secretions; it can be spread by droplet transmission, the faecal-oral route or direct contact with objects contaminated with an infected person's faeces or throat secretions. Poliomyelitis can also be caused by the use of a live attenuated oral polio vaccine (in Poland, OPV was withdrawn from the National Immunization Schedule in 2016). Between 01.2016 and 09.2017, polio cases associated with the circulating vaccine-derived Poliovirus (cVDPV) were reported from Syria (40 cases), the Democratic Republic of Congo (9), Laos (3), Nigeria (1) and Pakistan (1). The majority of polio infections are asymptomatic. In symptomatic cases, the course of the disease can be mild to severe. In its most severe form the infection causes muscle paralysis which may lead to death. Paralysis is observed in 1 per 200 cases; $5-10 \%$ of those affected by paralysis die, mostly as a result of the respiratory muscle paralysis. The disease is most often found in children under the age of 5 . The virus is excreted with faeces for a period of 6 weeks. The virus is most easily transmitted a few days before and about 3-4 weeks after the onset of symptoms. Humans are the only reservoir of the polio virus [17, 21].

Epidemiology. In 1988, 350,000 poliomyelitis cases were reported globally, since then (until August 2017) polio cases have decreased by $99 \%$. Despite this, new polio cases are still being observed which is the main reason for the delays in global polio eradication program. In its statement of 5 May 2014, the WHO proposed new guidelines on polio vaccination, in connection with the risk of importing wild Poliovirus (WPV) into polio-free countries. According to these guidelines, all residents or long-term travellers (over 4 weeks) to countries where WPV has been seen, who are planning to travel abroad in the next 4 weeks - 12 months, should be vaccinated against Poliovirus [15]. Between 2014 and $2015,85 \%$ of all polio cases were reported from Pakistan. In 2016, cases associated with wild polio strains were found in Pakistan (20), Afghanistan (13) and Nigeria (4). In 2017 (until 19 September), WPV poliomyelitis was found in Afghanistan (6 cases) and Pakistan (4). This means that all residents and long-term travellers staying over 4 weeks in polio-affected countries, i.e. Afghanistan, Pakistan and Nigeria who are planning to travel abroad should get vaccinated against the polio virus. Unless the transmission of the wild poliovirus is interrupted in all parts of the world, each country previously declared as polio-free is at risk from the re-emergence of the polio virus which may potentially lead to a new outbreak of the disease [21].

Risk for travellers. Vaccination against the Poliovirus is recommended for all travellers to or from endemic areas, or areas where the virus has re-emerged. Updated information on the transmission of wild type Poliovirus can be found on the website: www.polioeradication.org, under the tab Data and Monitoring [17].

Prevention. Poliomyelitis is best prevented by vaccination against Poliovirus. In Poland immunization against the virus is compulsory for all children under 6 years of age (in line with the National Immunization Schedule 2017). The inactivated poliovirus ()vaccine is administered in 4 doses. Adults who were vaccinated against Poliovirus in childhood and are travelling to countries where polio cases are being reported are recommended a single, inactivated booster dose of the vaccine. A number of different vaccines against poliovirus are available in Poland, including a monovalent vaccine (Imovax Polio), a combination vaccine against poliomyelitis, diphtheria, and tetanus (Dultavax) or against poliomyelitis, diphtheria, tetanus and pertussis (Boostrix Polio). According to the vaccination schedule, patients who have been immunised against these diseases should receive a single booster dose every 10 years [22].

\section{CHOLERA}

Cholera is a severe infectious disease of the gastrointestinal tract caused by the Vibrio cholerae bacteria. The disease is particularly dangerous and if left untreated it can lead to death in less than $20 \mathrm{~h}$. The disease is most commonly transmitted through the faecal-oral route, i.e. consumption of contaminated food or water (most commonly fish or seafood), less commonly, through direct physical contact with an infected person. The incubation period is short and takes from several hours to 5 days. The disease usually presents with severe watery diarrhoea. Excessive fluid loss and electrolyte imbalance lead to dehydration manifesting with dry mucosa, muscle spasms, renal or cardiac disorders. In severe cases, cholera may lead to a shock 
and eventually death. According the WHO, approximately $90 \%$ of cholera infections are asymptomatic or mild, especially among patients living in endemic areas. Therefore, in most cases it can be difficult to differentiate between cholera and other diarrheal disease if microbiological tests are not available. Cholera is highly contagious, and it must be remembered that a common source of the infection is usually the faeces of an infected person, even if this person is asymptomatic [17].

Epidemiology. The WHO estimates 1.3-4 million new cases and 21,000-143,000 deaths from cholera globally each year. In its latest full report on cholera prevalence, issued in 2015, the WHO reported of 172,000 cases found in 42 countries (16 countries in Africa: [Burundi, the Democratic Republic of Congo, Ghana, Cameroon, Kenya, Malawi, Mozambique, Niger, Nigeria, Somalia, South Sudan, Tanzania, Togo, Uganda, Ivory Coast, Zimbabwe] - 71,176 cases; 13 countries in Asia [Afghanistan, Bahrain / imported, Burma, China, India, Iraq, Iran, Japan / imported, Kuwait / imported, Malaysia, Nepal, Oman / imported, Thailand] - 64,590 cases; 6 countries in Europe [imported cases in France, Spain, Norway, Switzerland, Sweden, United Kingdom] - 22 cases; 6 countries in North and South America [the Dominican Republic, Haiti, Canada / imported, Cuba, Mexico, the United States of America] - 36,664 cases; 2 imported cases in Australia), including 1,304 deaths (in 23 countries). In 2015, 80\% of all cholera cases were reported from Afghanistan (58,064 cases), Haiti $(36,045)$, the Democratic Republic of Congo $(19,182)$, Kenya $(13,291)$ and Tanzania $(11,563)$ [23]. A large cholera outbreak was reported from Yemen in April 2017; until 21 September, or within 5 months only, over 704,000 cases were diagnosed, including 2,103 deaths [24]. Over the last decade, a majority of cholera cases were seen in Haiti; 813,000 cases and 9,676 deaths of cholera were reported there from October 2010 until mid-August 2017 [25].

Risk for travellers. Travellers to cholera endemic areas in Africa, Asia and the Caribbean are most at risk of developing cholera, especially if they tend to ignore the rules regarding food and feeding hygiene.

Prevention. Prevention is primarily concentrated on the introduction of effective sanitation and water treatment practices. A traveller to a developing country should pay particular attention to proper hygiene practices, especially washing hands each time after using the toilet. Also, they should always follow the rule: 'boil it, cook it, peel it or forget it'. The disease may be effectively prevented with an oral inactivated vaccine. Currently, there are three vaccines against cholera recommended by the WHO. These are: Dukoral (Valneva, Sweden), Shanchol (manufactured in India) and Euvichol (manufactured in South Korea). All the vaccines require 2 doses for full protection. Cholera vaccines are orally administered, which means patients need to abstain from eating and drinking at least $1 \mathrm{~h}$ before and $1 \mathrm{~h}$ after receiving the vaccine. Dukoral is the only cholera vaccine registered and available in Poland. It is an oral vaccine consisting of killed whole-cell V. cholerae 01 of several strains (Inaba and Ogawa serotypes, classical and EI Tor biotypes) and purified recombinant cholera $B$ subunit ( $\mathrm{rCTB}$ ). The vaccine also provides protection against enterotoxic ETEC due to the structural and immunological similarities between the LT-ETEC and rCTB (cross protection). The primary course consists of 2 doses given at an interval of 1-6 weeks for children over 6 years and adults (in children aged 2-6 years the vaccine is administered in 3 doses at the intervals of 1-6 weeks). The vaccine confers immunity against cholera for the next 2 years in children over 6 years of age and in adults (in children aged 2-6 years the immunity persists for 6 months). After this period, a booster dose needs to be administered. All doses of the vaccine should be taken at least 1 week before the planned departure into endemic areas $[15,17]$.

\section{TYPHOID FEVER}

Typhoid fever is an acute contagious disease caused by Salmonella typhi. The disease is generally transmitted through the faecal-oral route, i.e. consumption of contaminated water or food. Less frequently, the disease may be transmitted through direct physical contact with an infected individual or an asymptomatic carrier. The common signs and symptoms include: a gradually progressing fever, headaches, fatigue, loss of appetite, abdominal pain, diarrhoea or constipation, skin rash. A patient may develop severe complications including intestinal perforation, peritonitis, sepsis, encephalitis or neuropsychiatric disorders [17].

Epidemiology. Typhoid fever is a cosmopolitan disease. The risk of developing an infection is higher in areas lacking adequate food and feeding hygiene. Contaminated water supply reservoirs may also become the source of infection. Globally, an estimated 21 million new cases are reported each year; 200,000 of the cases are fatal (data from 2014) [15].

Risk for travellers. The highest risk for typhoid fever is reported in developing countries in Asia, Africa, Central and South America. 80\% of all typhoid cases are found in South Asia (Bangladesh, India, Pakistan, Nepal), South-East Asia (Vietnam, Laos) and in China.

Prevention. The most effective method of preventing the disease is by vaccination and proper food and feeding hygiene, especially for travellers to South and South-East Asia planning to use local dining facilities. Currently, there are two types of vaccine against typhoid available in Poland: a vaccine containing inactivated, heat and formalin-killed Salmonella typhi bacteria, and a vaccine containing the purified Vi capsular polysaccharide Vi Salmonella typhi. The 
vaccines are used to provide protection against typhoid, they do not, however, protect against other paratyphoid fevers. The inactivated vaccine is administered in 3 doses (month $0,1,6-12$ ); a booster is given every $3-5$ years following the primary course. The Vi capsular polysaccharide vaccine is administered in 1 dose and the efficacy of the vaccine lasts for 3 years (following this period a booster dose is recommended). The vaccine needs to be taken at least 1 week before the planned departure $[26,27]$.

\section{HEPATITIS A}

Hepatitis $\mathbf{A}$ is a disease of the digestive tract caused by the hepatitis A virus (HAV). The disease may be asymptomatic, or may present with moderate to severe signs and symptoms. The disease can be transmitted through direct physical contact with an infected person but also through the faecal-oral route, i.e. drinking contaminated water or beverages (also contaminated ice cubes), eating shellfish caught from contaminated waters, consumption of raw fruit and vegetables. HAV is resistant to freezing; frozen foods can be the source of infection as well. The incubation period of hepatitis A is typically 2 to 6 weeks, the most common signs and symptoms include fever, loss of appetite, nausea, vomiting and jaundice. The virus is excreted with faeces for a period of 6 weeks but is easily transmitted 2--3 weeks before symptoms appear.

Epidemiology. Viral hepatitis A is a cosmopolitan disease, i.e. it is found worldwide. The endemicity level much depends on the geographical region and the level of hygiene and standards of sanitation in a given area.

Risk for travellers. The risk of infection with viral hepatitis A increases in areas with poor standards of hygiene and sanitation, especially if foreign visitors use local dining facilities [17].

Prevention. To prevent hepatitis A, travellers need to maintain good food and feeding hygiene, but the best way to avoid infection is to get vaccinated. The monovalent inactivated HAV vaccines available in Poland are administered in 2 doses at the interval of $6-12$ months (according to the manufacturers, the second dose of Avaxim should be taken no later than 36 months after the initial dose, while the second dose of Havrix Adult needs to be received no later than 5 years after the primary course). The first dose of the vaccine should be taken at least 2-4 weeks before travel. The WHO does not recommend the administration of a booster dose (the level of antibodies produced after the primary course of vaccination persists for at least 25 years). $A$ combined vaccine against hepatitis $A$ and $B$ is also used in Poland; it is administered in 3 doses at months $0,1,6$. Also, an accelerated combined vaccination course is available: the vaccine is taken on days $0,7,21$, and patients receive a single booster dose 12 months after the primary course $[28,29]$.

\section{HEPATITIS B}

Hepatitis B is a contagious disease caused by the lymphotropic and hepatotropic hepatitis B virus (HBV). HBsAg, the surface antigen of the hepatitis $B$ virus, is responsible for its strong immunogenicity. HBV strains have been classified into four groups (ayw, adw, ayr, adr); all of the strains have the same clinical presentation. The common modes of transmission include: blood transfusion or blood products transfusion, direct contact with infected bodily fluids (saliva, mucus, sperm), sexual contacts, vertical transmission, i.e. from a mother to her baby, accidental or deliberate punctures with contaminated needles (e.g., accidental needlestick injuries, re-use of contaminated needles and syringes, piercing, tattooing, acupuncture). Hepatitis B infection may be asymptomatic or it may present with moderate to severe signs and symptoms. In some cases it may develop into a chronic form and eventually lead to cirrhosis or liver cancer. HBV infected individuals are the major source of transmission. HBV is much more infectious than HIV and it is more resistant to environmental factors and chemical agents. The most common symptoms of HBV infection include fatigue, loss of appetite, nausea, abdominal pain and jaundice. The incubation period is normally 3-4 months but it can range between 6 weeks and 6 months [17].

Epidemiology. Hepatitis $B$ is a cosmopolitan disease. According to $\mathrm{WHO}$, an estimated 257 million people worldwide are infected with the hepatitis B virus. In 2015, hepatitis $B$ was the cause of 887,000 deaths, mostly from complications such as liver cancer or cirrhosis. The highest prevalence rates of HBV infections are reported from Africa and Oceania (over $6 \%$ of the adult population), in the Middle East, Central Asia and North-East Africa (3.3\% of the general population) and South-East Asia (2.0\% of the general population) [15].

Risk for travellers. The main factors determining the risk of infection with HBV while traveling overseas are: high incidence of the disease in a given population and exposure to infectious blood or other bodily fluids. The risk of becoming infected with hepatitis B increases if travellers engage in casual sex or receive injections (medications, intravenous drugs).

Prevention. While travelling to endemic countries, travellers should avoid casual sexual contacts and exposure to contaminated needles (piercing, tattoos). Yet, the most effective form of prevention against hepatitis $B$ is vaccination. There are several monovalent hepatitis $B$ vaccines available in Poland. Each contains a different dose of HBsAg, depending on the manufacturer (Engerix B, Euvax, HBVAX $P R O)$. The vaccines are administered in 3 doses (months $0,1,6)$. No less than 2 doses of the vaccine should be administered at least 2 weeks before travel. A combined vaccine against hepatitis $A$ and $B$ (a single injection) is also 
used in Poland; it is administered in 3 doses at months $0,1,6$. An accelerated combined vaccination course is given on days $0,7,21$; patients receive a single booster dose 12 months after the primary course. According to the WHO recommendations it is not necessary to receive a booster dose of a HBV vaccine since the level of antibodies produced after the primary course of vaccination persists for many years after. To assess the response to HBV vaccine, the anti-HBs antibodies test is performed (in non-vaccinated patients, the presence of anti-HBs antibodies indicates a HBV infection in the past). The test is performed no earlier than 4 weeks after the administration of the last dose of the primary immunisation course (best between week 4 and 6). The concentration of the anti-HBs antibodies should be higher than $10 \mathrm{IU} / \mathrm{L}$ (however, according to the National Immunisation Programme, even if the concentration of the anti-HBs antibodies is lower than $10 \mathrm{IU} / \mathrm{L}$ booster doses are not required for previously vaccinated healthy individuals). A booster dose or a regular anti-HBs test (every 6-12 months) is only recommended for patients with renal diseases and the glomerular filtration rate less than $30 \mathrm{~mL} / \mathrm{min}$ and for dialysis patients [30-32].

\section{DIPHTHERIA}

Diphtheria is an acute bacterial disease caused by toxic strains of Corynebacterium diphtheriae. It is spread by droplet contact or direct physical contact with an infected individual. Diphtheria affects the mucous membrane of the respiratory tract (upper respiratory tract diphtheria), skin, or less commonly, other parts of the body (eyes, nose, sex organs). The incubation period is $2-5$ days. Diphtheric lesions, usually affecting the upper respiratory tract mucosa (throat, tonsils, larynx), are often covered by necrotic pseudomembrane. The bacteria produce a toxin which can spread through the body and cause serious complications, e.g. myocarditis [17].

Epidemiology. Diphtheria is a cosmopolitan disease. Currently, WHO is promoting and conducting mass DTP3 (diphtheria, tetanus, pertussis) immunisation campaigns targeting children worldwide (an estimated global vaccination coverage is $86 \%$; the lowest, less than $50 \%$ is reported from Somalia, South Sudan, Central African Republic, Syria and Ukraine). Despite these efforts, diphtheria infections are still being reported from South Asia (India), South-East Asia (Indonesia, Laos, Burma) and East Africa (Madagascar). In 2015 , a total of 4,530 cases of diphtheria (including 2,365 in India and 1,627 in Madagascar) were reported globally. In 2016, diphtheria prevalence increased in India $(3,380)$ and in Madagascar $(2,865)$.

Risk for travellers. The disease is potentially life-threatening. Severe complications may occur in individuals who have not been immunised. The disease is far more common in areas where vaccination rates are low among the local population [15].

Prevention. In Poland, vaccination against diphtheria is a part of the National Immunisation Programme and is administered to all children under 19. Patients who have been vaccinated in childhood are recommended a single, booster dose every 10 years; for patients who have not been immunized a primary course of the vaccination is recommended. There are two combination vaccines against diphtheria available in Poland; the first one provides protection against diphtheria, tetanus, poliomyelitis (Dultavax) and the other one against diphtheria, tetanus, pertussis and poliomyelitis (Boostrix Polio). Adults who have been immunized in the past need to receive a booster dose every 10 years $[17,33]$.

\section{TETANUS}

Tetanus is an acute infectious disease caused by a neurotoxin produced by anaerobic bacillus Clostridium tetani. Infection typically occurs through contamination of a wound with soil, animal manure fertilizer, dust or other foreign body infected with tetanus spores. The incubation period is from 3 days to 3 weeks (usually 8 days). Symptoms of the disease include muscle stiffness and painful spasms which first develop in the jaw and neck muscles. Severe tetanus may lead to respiratory failure and eventually death [17].

Epidemiology. Contamination of a wound with tetanus spores (Clostridium tetani) may occur in any part of the world, especially in the developing countries in Africa and Asia. Currently, the WHO is promoting mass DTP3 (diphtheria, tetanus, pertussis) immunisation campaigns targeting children worldwide (an estimated global vaccination coverage is $86 \%$; the lowest, less than $50 \%$ is reported from Somalia, South Sudan, Central African Republic, Syria and Ukraine). Tetanus prevalence is high in South Asia (India, Nepal, Bangladesh, Pakistan), South East Asia (Philippines, Vietnam) and East Africa (Kenya, Uganda). In 2015, a total of 10,337 tetanus cases were reported globally (including 2,268 in India and 1,804 in Uganda). In 2016, there was an increase in tetanus prevalence in India $(3,781)$, Kenya $(2,776)$ and the Philippines (1,082) [15].

Risk for travellers. Basically each type of a puncture wound, no matter if it is merely a skin cut or a severe multiorgan injury, may result in a tetanus infection especially in non-vaccinated individuals.

Prevention. In Poland vaccination against tetanus is a part of the National Immunisation Programme and is administered to all children under 19. Adult patients who have been vaccinated in childhood are recommended a single, booster dose to be taken every 10 years; for patients who have not been immunised a primary course of the vaccination is recommended. The vaccine is also recommended for 
employees whose work responsibilities involve contact with soil, workers employed at the disposal of solid and liquid waste, and those responsible for the maintenance of devices used for that purpose, as well as travellers to tetanus endemic countries. There are two combination vaccines against tetanus available in Poland; the first one provides protection against diphtheria, tetanus, poliomyelitis (Dultavax) and the other one against diphtheria, tetanus, pertussis and poliomyelitis (Boostrix Polio). Adults who have been immunized in the past need to receive a booster dose every 10 years $[17,33]$.

\section{RABIES}

Rabies is a fatal infectious disease caused by the neurotropic Lyssavirus virus of the Rhabdoviridae family. The disease is nearly always transmitted through a bite from an infected animal or exposure of damaged skin or mucosa to contaminated saliva. The incubation period is on average 20-29 days, but it may be as long as several months (the incubation period is shorter if the bitten site is highly innervated). The first signs manifest at the earliest after 10 days from the virus transmission. In humans, the signs and symptoms of rabies include paraesthesia at the site of the bite, anxiety, sweating, increased salivation and enlarged pupils. An infected person may also experience painful muscle spasms while swallowing, breathing difficulty and seizures. Death usually occurs in less than a week after the onset of initial symptoms [17].

Epidemiology. Rabies is a cosmopolitan disease. The WHO regularly updates the list of countries reporting new cases of rabies infections. Currently, the list includes 90 countries from Asia, Africa, Central and South America. There are an estimated 55,000 deaths from rabies worldwide each year. The infection is most frequently transmitted by a bite from infected dogs (95\% of human rabies), less often from cats, bats, wild predators. A majority of cases are reported from India (approx. 20,000 cases annually), but also from countries in South and South-East Asia (Afghanistan, Pakistan, Bangladesh, Nepal, Burma, Cambodia) and Africa (the Democratic Republic of Congo, Burkina Faso, Niger, Nigeria, Ethiopia, Somalia, Kenya, Tanzania, Mozambique).

Risk for travellers. The highest risk of rabies transmission is from stray dogs. Children under the age of 15 are at the greatest risk of transmission ( $40 \%$ of all cases) because they are smaller than adults and may be bitten more severely, also, they are keen to play with animals, and if they have been bitten they often fail to inform anyone of the fact). Cave explorers need to keep in mind that rabies can also be transmitted by bats [17].

Prevention. Travellers to rabies endemic countries, especially in Asia and Africa, are recommended pre-exposure vaccination. If they are bitten by a potentially infected ani- mal, they must receive post-exposure vaccination as well. They should avoid contact with stray animals, mainly cats and dogs, but also with wild undomesticated animals. They should never approach, touch or stroke any animals, even if they are domesticated and behave in a friendly manner. Pre-exposure vaccination against rabies is administered in 3 doses for both children and adults. The vaccine is given on days: $0,7,28$ (according to the WHO recommendations on days: $0,7,21$ or 28$)$. A complementary dose is administered a year after the primary course. In order to increase the vaccine efficacy, a booster dose is recommended to be taken every 5 years. All three doses of the primary immunization course should be taken at least 3 weeks before travel to endemic areas. An inactivated rabies vaccine, containing a killed virus which is grown in a VERO cell line (Verorab), is available and used in Poland [17].

Post-exposure vaccinations. Patients who have received pre-exposure vaccination (in the last 5 years) are given 2 doses of the vaccine: the first dose on the day of being bitten and the second dose 3 days later. Individuals who have not been immunised (they received pre-exposure vaccination more than 5 years before being bitten, they have not received all doses of the vaccine or have never taken pre-exposure vaccination) receive 5 doses of the post-exposure vaccine on days: 0 (the day of being bitten), $3,7,14$ and 28. Before administering the first dose of the vaccine, a non-immunized individual should also receive immunoglobulin RIG (HRIG: 20 IU/kg body mass or ERIG: $40 \mathrm{IU} / \mathrm{kg}$ body mass) [34].

\section{JAPANESE ENCEPHALITIS}

Japanese encephalitis is a viral disease affecting the CNS caused by the viruses of the Flaviviridae family. The disease is transmitted through a bite from an infected mosquito. The natural hosts of the Japanese encephalitis virus are wading birds that inhabit wetland areas as well as pigs bred in rural areas. The majority of cases are asymptomatic or present with mild flu-like symptoms including fever, headaches and gastrointestinal disorders. A vast majority of cases presenting with clinical symptoms is found in children under 10 years of age, and $75 \%$ of all infections are diagnosed in children under 15 years of age. Approximately $1 \%$ of the infected individuals develop disorders of the CNS (encephalitis, disorders of consciousness, paresis) with mortality rate reaching $30 \%$ of those affected [17].

Epidemiology. The transmission of Japanese encephalitis virus has been reported from 22 countries in Asia and from Australia and Oceania (Yorke peninsula, Queensland, Papua New Guinea). The WHO estimates nearly 68,000 clinical cases globally each year, including 10,000-20,000 deaths. Since most patients with Japanese encephalitis are asymptomatic, the reported cases constitute only a small 
part of the actual number of cases. In 2016, a total of 5,399 new cases of Japanese encephalitis were reported from 17 countries. The highest prevalence was reported from India (1,627), Bangladesh (1,294), China $(1,130)$, Burma (393), Vietnam (357) and the Philippines (312) [15].

Risk for travellers. The risk of contracting Japanese encephalitis increases in rural areas or wetland areas a natural habitat for mosquitoes, i.e. vectors of the infection.

Prevention. Because there is no specific causative treatment for Japanese encephalitis, prevention against vectors (mosquitoes) of the infection is crucial. To minimise the risk of infection travellers are recommended to use insect repellents, wear long-sleeved shirts or tops and long trousers and avoid staying outdoors after dark, especially in areas close to standing water. An inactivated vaccine, containing killed Japanese encephalitis virus grown in a VERO cell line (Ixiaro), is available and used in Poland. In adults, the vaccine is administered in 3 doses: the first dose on day 0 , the second dose on day 7 or 28 , the third - a complementary dose is administered 12-24 months after the primary one. There are no data available regarding the need to administer a booster dose in adult patients. Children over 3 years of age receive the vaccination in 2 doses: on day 0 and 28 . Both doses of the vaccine should be taken at least 7 days before travel to endemic areas [35, 36].

Vaccinations recommended for travellers to popular diving sites are summarised in Table 3.

\section{MALARIA CHEMOPROPHYLAXIS}

Malaria is a protozoan disease caused by five species of the Plasmodium genus: P. falciparum, P. vivax, P. malariae, $P$. ovale and $P$. knowlesi. It is transmitted to humans through a bite from an infected female Anopheles mosquito (by injecting invasive Plasmodium forms into the bloodstream of a human host), through blood transfusion, or vertically, from an infected mother to her child. Plasmodium parasites invade the human liver and the red blood cells. The disease vectors in malaria-endemic areas are found at the altitude of up to 2000-2200 m above the sea level (with the exception of certain malaria-prone areas in Afghanistan, Bolivia, Ethiopia, Eritrea, Kenya and Pakistan where cases of the disease are observed at the altitudes of 2200-2500 m above the sea (evel). An estimated 3 billion people in 95 countries live in malaria-endemic areas. According to the estimates from the WHO there were 214 million new cases of malaria in 2015 (88\% in Africa, 80\% in 17 countries and as much as $40 \%$ in 3 countries only: the Democratic Republic of Congo, Nigeria and India. In the same year the WHO reported of 438,000 deaths from malaria $(90 \%$ in Africa, $70 \%$ in children under the age of $5,80 \%$ cases in 14 countries, and $47 \%$ in 6 countries: Nigeria, the Democratic Republic of Congo, Tanzania, Uganda, Mozambique and Ivory Coast). Plasmodium falciparum and $P$. vivax are the most common etiological factors of malaria globally (80-95\% cases). In highly developed countries (North America, Western Europe) there are approximately 10,000 imported malaria cases, mainly from Sub-Saharan Africa and South-East Asia. Sporadically, there are reports of the so-called 'airport malaria', i.e. cases of malaria occurring in and near international airports or sea ports and caused by infected mosquitoes transported by a ship or aircraft from malaria-endemic areas [17]. In Europe, domestic cases of malaria were reported from Greece in 2013 and then again in 2016 (in total, 12 districts were affected, including Thessaloniki and the Peloponnese) [37]. In Poland, 20 to 30 cases of malaria are diagnosed yearly; all of which are imported cases. After an incubation period lasting from 9 to 40 days depending on the species of Plasmodium, clinical symptoms appear in three typical stages: a cold stage accompanied with shivers and chills, a hot stage during which the body temperature reaches $40^{\circ} \mathrm{C}$ with symptoms including dry skin and mucosa, consciousness disturbances, abdominal pain due to splenomegaly, and finally a sweating stage with a sudden drop in body temperature and massive sweating. In Plasmodium vivax and $P$. ovale infections, fever paroxysms occur periodically every $48 \mathrm{~h}$ (tertian fever), in P. malariae infection - every $72 \mathrm{~h}$ (quartan fever). Fever paroxysms in $P$. falciparum malaria are irregular and elevated body temperature of varying degree can persist all throughout the duration of the symptomatic disease. Fever paroxysms in malaria may be accompanied by headaches, muscle pain, nausea, vomiting, diarrhoea, hepatomegaly and splenomegaly. Fever paroxysms gradually become less severe and if there are no complications, symptoms normally disappear within several weeks. P. falciparum malaria is the most severe form of malaria and may cause serious complications. The mortality rate of $P$. falciparum malaria reaches $15-20 \%$. The life-threatening complications of severe malaria include: coma, focal CNS damage, acute respiratory failure, severe anaemia, thrombocytopenic haemorrhagic diathesis and/or disseminated intravascular coagulation, acute renal failure.

The principal preventive measures against malaria include:

- the use of appropriate malaria drug regimens: atovaquone/proguanil, doxycycline, mefloquine or chloroquine;

- the use of mosquito nets, insect repellents (containing 30-50\% DEET - N,N-diethyl-meta-toluamide or $20 \%$ picaridin e.g. Moskito Guard), wearing proper clothing (long-sleeved shirts or tops, long trousers);

- staying indoors after dark (when mosquitoes are the mostactive) especially in areas close to standing water (ponds, lakes);

- staying in air-conditioned accommodation with insect screens on all windows and ventilation grills. 
Table 3. Vaccinations recommended for travellers to countries popular among divers. Source: [17]

\begin{tabular}{|c|c|c|c|c|c|c|c|c|c|}
\hline Country & 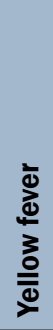 & 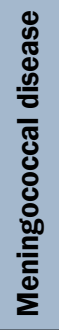 & $\frac{\pi}{\frac{\pi}{2}}$ & $\begin{array}{l}\text { 등 } \\
\text { 듬 } \\
\text { 글 }\end{array}$ & 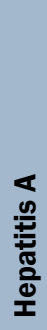 & 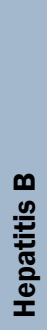 & 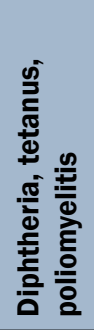 & $\frac{\mathscr{d}}{\stackrel{0}{0}}$ & 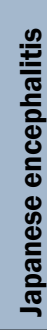 \\
\hline \multicolumn{10}{|l|}{ South-East Asia } \\
\hline Philippines & & & $x$ & $x$ & $x$ & $x$ & $x$ & $x$ & $x$ \\
\hline Indonesia & & & $x$ & $x$ & $x$ & $x$ & $x$ & $x$ & $x$ \\
\hline Malaysia & & & $x$ & $x$ & $x$ & $x$ & $x$ & $x$ & $x$ \\
\hline Thailand & & & $x$ & $x$ & $x$ & $x$ & $x$ & $x$ & $x$ \\
\hline \multicolumn{10}{|l|}{ Indian Ocean } \\
\hline Andaman Islands (India) & & & & $x$ & $x$ & $x$ & & & \\
\hline Maldives & & & & $x$ & $x$ & $x$ & & & \\
\hline Mauritius & & & & $x$ & $x$ & $x$ & & & \\
\hline Seychelles & & & & $x$ & $x$ & $x$ & & & \\
\hline \multicolumn{10}{|l|}{ Pacific Ocean } \\
\hline Fiji & & & & $x$ & $x$ & $x$ & & & \\
\hline Palau & & & & $x$ & $x$ & $x$ & & & \\
\hline \multicolumn{10}{|c|}{ Central America and the Caribbean } \\
\hline Belize & & & & $x$ & $x$ & $x$ & & $x$ & \\
\hline Cayman Islands & & & & $x$ & $x$ & $x$ & & & \\
\hline Costa Rica & & & & $x$ & $x$ & $x$ & & $x$ & \\
\hline Mexico & & & $x$ & $x$ & $x$ & $x$ & $x$ & $x$ & \\
\hline \multicolumn{10}{|l|}{ Red Sea } \\
\hline Egypt & & & & $x$ & $x$ & $x$ & $x$ & $x$ & \\
\hline \multicolumn{10}{|l|}{ Mediterranean Sea } \\
\hline Croatia & & & & & $x$ & $x$ & & & \\
\hline Greece & & & & & $x$ & $x$ & & & \\
\hline France & & & & & $x$ & $x$ & & & \\
\hline Spain & & & & & $x$ & $x$ & & & \\
\hline Italy & & & & & $x$ & $x$ & & & \\
\hline Malta & & & & & $x$ & $x$ & & & \\
\hline Tunisia & & & & & $x$ & $x$ & & $x$ & \\
\hline
\end{tabular}

The Centres for Disease Control and Prevention as well as the WHO recommend that travellers to malaria endemic areas should use one of the following drug regimens:

- atovaquone/proguanil - the drug has the fewest side effects of all the recommended antimalarials (rarely: gastrointestinal disorders, allergic rash, headaches);

- doxycycline - the drug has a large number of side effects and can cause nausea, vomiting, oral or vaginal yeast infections, hepatotoxicity, hypersensitivity to sunlight, photodermatoses;

- mefloquine - possible side effects include neuropsychiatric disorders, thus the medication is contraindicated for some professionals, e.g. aircraft crews;

- chloroquine - the emergence of chloroquine-resistant plasmodium has had a significant impact on the application of chloroquine to treat malaria; currently the drug 
Table 4. Drugs used for antimalarial chemoprophylaxis. Source: [17]

\begin{tabular}{|c|c|c|c|}
\hline Name of drug & Dosage & Duration of chemoprophylaxis & Note \\
\hline $\begin{array}{l}\text { atovaquone/ } \\
\text { /proguanil }\end{array}$ & $\begin{array}{l}1 \times \text { day } \\
11-20 \mathrm{~kg} \text { bw: } 62.5 \mathrm{mg} / 25 \mathrm{mg} \\
\text { (paediatric tablet) } \\
21-30 \mathrm{~kg} \text { bw: } 2 \text { paediatric tablets } \\
31-40 \mathrm{~kg} \text { bw: } 3 \text { paediatric tablets } \\
>40 \mathrm{~kg} \text { bw: } 250 \mathrm{mg} / 100 \mathrm{mg} \\
\text { (adult tablet) } 1 \times 1 \text { tablet }\end{array}$ & $\begin{array}{l}1 \text { day before travel, } \\
\text { every day during travel, } \\
7 \text { days after travel }\end{array}$ & $\begin{array}{l}\text { Concurrent intake of metoclopramide } \\
\text { or tetracycline results in a lower } \\
\text { plasma concentration of the drug } \\
\text { very rare gastrointestinal, } \\
\text { dermatological adverse events }\end{array}$ \\
\hline doxycycline & $\begin{array}{l}1 \times \text { day } \\
\text { adults: } 1 \text { tablet } 100 \mathrm{mg}\end{array}$ & $\begin{array}{l}1 \text { day before travel, } \\
\text { every day during travel, } \\
28 \text { days after travel }\end{array}$ & $\begin{array}{l}\text { Gastrointestinal, dermatological, } \\
\text { gynaecological adverse events }\end{array}$ \\
\hline mefloquine & $\begin{array}{l}1 \times \text { week } \\
\text { adults: } 1 \text { tablet } 250 \mathrm{mg}\end{array}$ & $\begin{array}{l}1 \text { week before travel, } \\
1 \times \text { week during travel, } \\
4 \text { weeks after travel }\end{array}$ & $\begin{array}{l}\text { Concurrent intake of ampicillin, tetra- } \\
\text { cyclines or metoclopramide results in } \\
\text { a higher plasma concentration of the } \\
\text { drug neuropsychiatric adverse events }\end{array}$ \\
\hline chloroquine & $\begin{array}{l}1 \times \text { week } \\
\text { adults: } 300 \mathrm{mg}(2 \text { tablets } 150 \mathrm{mg})\end{array}$ & $\begin{array}{l}1 \text { week before travel, } \\
1 \times \text { week during travel, } \\
4 \text { weeks after travel }\end{array}$ & $\begin{array}{l}\text { Contraindicated in epilepsy and } \\
\text { psoriasis }\end{array}$ \\
\hline
\end{tabular}

is only to be used in certain regions of the world (Central America, North Africa, some Middle East countries) [17] (Tables 4, 5).

\section{STAND-BY EMERGENCY TREATMENT (SBET)}

In case of a fever of unknown origin occurring in tourists travelling to malaria-endemic regions where diagnostic tests which might confirm or rule out malaria are unavailable, the WHO recommends the self-use of a stand-by emergency treatment. SBET is also advised to contract workers offered short-term overseas employment in malaria-endemic regions. Coartem (artemether $20 \mathrm{mg} /$ lumefantrine $120 \mathrm{mg}$ ) is now the most widely used emergency medication for the treatment of malaria. The drug is to be taken in 6 doses over 3 consecutive days: 0, 8, 24, 36, 48, 60 (hours) - body weight: $5-14 \mathrm{~kg}$ : 1 tablet $(20 \mathrm{mg} / 120 \mathrm{mg}) /$ a single dose; 15-24 kg bw: 2 tablets (40 mg/240 mg)/a single dose; 25-34 kg bw: 3 tablets (60 mg/360 mg)/a single dose; over $34 \mathrm{~kg}$ bw: 4 tablets $(80 \mathrm{mg} / 480 \mathrm{mg}$ )/a single dose. SBET is also advised to contract workers offered short-term overseas employment (lasting from several days to several months) in malaria-endemic regions, if the risk of possible side effects associated with standard chemoprophylaxis is higher than the risk of malaria transmission. In Switzerland and Great Britain arthemeter/lumefantrine has been registered for stand-by emergency treatment of malaria in travellers [17].

\section{TRAVEL HEALTH KIT}

Preparing and packing a travel health kit is as important as receiving all preventive vaccinations and taking antimalarial chemoprophylaxis and/or preparing standby emergency treatment of malaria (SBET). Before travelling abroad make sure you pack all the necessary medications, dressing materials and documents e.g. The International Certificate of Vaccination, a health insurance card, a copy of your passport and passport photographs which may be necessary to obtain entry visas. These include:

- prescription medicines for chronic diseases, contraceptive medications and antimalarials for the whole period of travel (these should be kept in the hand luggage in the original packaging in case of a thorough inspection by border guards);

- when travelling by plane you should keep in mind certain security requirements on the transport of liquids (drugs in the form of suspensions, syrups or cosmetics). Liquid containers larger than $100 \mathrm{~mL}$ must be placed in checked baggage, containers smaller than $100 \mathrm{~mL}-$ may be carried in the hand luggage, but must be stored in a sealed transparent plastic bag;

- antimalarial medication;

- insect repellent;

- antidiarrheal medication;

- medications for the respiratory tract infections;

- medications for the urinary tract infections;

- analgesic, antipyretic;

- antihistamine;

- adrenaline prefilled syringe for individuals allergic to hymenoptera venom;

- motion sickness medication;

- anti-inflammatory/antimicrobial/antifungal ointments and creams;

- after-bite anti-itch gel;

- skin disinfectants;

- ear and eye drops;

- dressing materials (gauze, bandage), scissors, tweezers, gloves; 
Table 5. Recommended antimalarial chemoprophylaxis in countries popular among divers. Source: [37]

\begin{tabular}{|c|c|c|c|}
\hline Country & Epidemiology & $\begin{array}{l}\text { Chloroquine } \\
\text { resistance }\end{array}$ & $\begin{array}{l}\text { Recommended } \\
\text { chemoprophylaxis }\end{array}$ \\
\hline \multicolumn{4}{|c|}{ South-East Asia } \\
\hline $\begin{array}{l}\text { The } \\
\text { Philippines }\end{array}$ & $\begin{array}{l}\text { Rural areas below } 600 \text { m above sea level except for } 22 \text { provinces: Aklan, } \\
\text { Albay, Benguet, Biliran, Bohol, Camiguin, Capiz, Catanduanes, Cavite, } \\
\text { Cebu, Guimaras, Iloilo, Northern Leyte, Southern Leyte, Marinduque, Mas- } \\
\text { bate, Easter Samar, Northern Samar, Western Samar, Siquijor, Sorsogon, } \\
\text { Surigao Del Norte. No risk of malaria transmission in the country's capital, } \\
\text { Manila or in urban areas. }\end{array}$ & Confirmed & $\begin{array}{l}\text { atovaquone/proguanil, } \\
\text { doxycycline or mefloquine }\end{array}$ \\
\hline Indonesia & $\begin{array}{l}\text { Eastern parts of the country (provinces: Maluku, Maluku Utara, Nusa } \\
\text { Tenggara Timur, Papua and Papua Barat), including the city of Labuan } \\
\text { Bajo and the Komodo Islands (Nusa Tenggara); rural areas: Kalimantan } \\
\text { (Borneo), Nusa Tenggara Barat (including the island of Lombok), Sulawesi, } \\
\text { Sumatra. Low risk of transmission in rural areas in Java (including Ujung } \\
\text { Kulong, Sukalumi and Pangandaran). No risk of transmission in Jakarta, } \\
\text { Ubud and in seaside resorts in Bali, Java, Gili Islands and Thousand } \\
\text { Islands (Pulau Seribu) }\end{array}$ & Confirmed & $\begin{array}{l}\text { atovaquone/proguanil, } \\
\text { doxycycline or mefloquine }\end{array}$ \\
\hline Malaysia & $\begin{array}{l}\text { Rural areas, especially forests in Borneo (Sabah and Sarawak provinces) } \\
\text { and the peninsula. No risk of transmission In large cities and at the seasi- } \\
\text { de (Kuala Lumpur, Georgetown, Penang State including Penang Island) }\end{array}$ & Confirmed & $\begin{array}{l}\text { atovaquone/proguanil, } \\
\text { doxycycline or mefloquine }\end{array}$ \\
\hline Thailand & $\begin{array}{l}\text { Provinces along the border with Cambodia, Laos and Myanmar (Burma), } \\
\text { also provinces: Kalasin, Krabi (Plai Phraya district), Nakhon Si Thammarat, } \\
\text { Narathiwat, Pattani, Phang Nga (including the city of Phang Nga), Rayong, } \\
\text { Sakon Nakhon, Songkhla, Surat Thani and Yala, in particular wooded } \\
\text { areas in these provinces. Sporadic cases in other parts of Krabi province, } \\
\text { in large cities and seaside resorts: Bangkok, Chiang Mai, Chiang Rai, } \\
\text { Koh Samui, Koh Phangan, Phuket. No risk of transmission on the islands } \\
\text { in Krabi province (Koh Phi Phi, Koh Yao Noi, Koh Yao Yai, Ko Lanta) } \\
\text { and in Pattaya resort }\end{array}$ & $\begin{array}{l}\text { Confirmed; } \\
\text { mefloquine } \\
\text { resistance } \\
\text { also confirmed }\end{array}$ & $\begin{array}{l}\text { ONLY atovaquone/proguanil } \\
\text { or doxycycline - provinces } \\
\text { along the border with Cambo- } \\
\text { dia, Laos and Myanmar (Bur- } \\
\text { ma), also provinces: Kalasin, } \\
\text { Krabi (Plai Phraya district), } \\
\text { Nakhon Si Thammarat, } \\
\text { Narathiwat, Pattani, Phang } \\
\text { Nga (including the city of } \\
\text { Phang Nga), Rayong, Sakon } \\
\text { Nakhon, Songkhla, Surat } \\
\text { Thani and Yala; Bangkok, } \\
\text { Chiang Mai, Chiang Rai, Koh } \\
\text { Samui, Koh Phangan, Phuket } \\
\text { - repellents }\end{array}$ \\
\hline \multicolumn{4}{|c|}{ Indian Ocean } \\
\hline $\begin{array}{l}\text { Andaman } \\
\text { Islands } \\
\text { (India) }\end{array}$ & Sporadic cases among the local population & No data & Repellents \\
\hline Maldives & Not found & Not applicable & Not applicable \\
\hline Mauritius & Not found & Not applicable & Not applicable \\
\hline Seychelles & Not found & Not applicable & Not applicable \\
\hline \multicolumn{4}{|c|}{ Pacific Ocean } \\
\hline Fiji & Not found & Not applicable & Not applicable \\
\hline Palau & Not found & Not applicable & Not applicable \\
\hline \multicolumn{4}{|c|}{ Central America and the Caribbean } \\
\hline Belize & $\begin{array}{l}\text { Sporadic cases among the local population. No risk of transmission } \\
\text { in Belize City and the island visited by tourists (Ambergris Caye) }\end{array}$ & No & Repellents \\
\hline $\begin{array}{l}\text { Cayman } \\
\text { Islands }\end{array}$ & Not found & Not applicable & Not applicable \\
\hline Costa Rica & Not found & Not applicable & Not applicable \\
\hline
\end{tabular}


Table 5 cont. Recommended antimalarial chemoprophylaxis in countries popular among divers. Source: [37]

\begin{tabular}{|c|c|c|c|}
\hline Country & Epidemiology & $\begin{array}{l}\text { Chloroquine } \\
\text { resistance }\end{array}$ & $\begin{array}{l}\text { Recommended chemopro- } \\
\text { phylaxis }\end{array}$ \\
\hline Mexico & $\begin{array}{l}\text { Campeche, Chiapas, Chihuahua, Nayarit and Sinaloa districts; sporadic } \\
\text { cases in Durango, Jalisco, Oaxaca, Sonora and Tabasco districts, and } \\
\text { in Othon P. Blanco in the southern part of the Quintana Roo district } \\
\text { along the border with Belize. No risk of transmission along the } \\
\text { Mexican-American border }\end{array}$ & No & $\begin{array}{l}\text { atovaquone/proguanil, } \\
\text { doxycycline, mefloquine or } \\
\text { chloroquine - Campeche, } \\
\text { Chiapas, Chihuahua, Nayarit } \\
\text { and Sinaloa districts; } \\
\text { Durango, Jalisco, Oaxaca, } \\
\text { Sonora, Tabasco districts and } \\
\text { Othon P. Blanco In southern } \\
\text { parts of Quintana Roo district } \\
\text { - repellents }\end{array}$ \\
\hline \multicolumn{4}{|l|}{ Red Sea } \\
\hline Egypt & Not found & Not applicable & Not applicable \\
\hline \multicolumn{4}{|c|}{ Mediterranean Sea } \\
\hline Croatia & Not found & Not applicable & Not applicable \\
\hline France & Not found & Not applicable & Not applicable \\
\hline Greece & $\begin{array}{l}\text { In } 2016 \text { malaria cases were found among the local population. } \\
12 \text { districts were affected: Farkadona, Trikala, Palamas, Tempe, } \\
\text { Achaean, Thebes (Central Greece), Evrotas, Andravida-Kyllini } \\
\text { (Peloponnisos), Chalcis (Eubea), Marathon (Attica), Lagada, Pylaia } \\
\text { (Thessaloniki) }\end{array}$ & No data & $\begin{array}{l}\text { atovaquone/proguanil, } \\
\text { doxycycline or mefloquine in } \\
\text { following districts: Farkadona, } \\
\text { Trikala, Palamas, Tempe, } \\
\text { Achaean, Thebes, Evrotas, } \\
\text { Andravida-Kyllini, Chalcis, } \\
\text { Marathon, Lagada, Pylaia }\end{array}$ \\
\hline Spain & Not found & Not applicable & Not applicable \\
\hline Malta & Not found & Not applicable & Not applicable \\
\hline Tunisia & Not found & Not applicable & Not applicable \\
\hline Italy & Not found & Not applicable & Not applicable \\
\hline
\end{tabular}

- an extra pair of glasses or contact lenses (travellers with a sight defect);

- sunglasses;

- sunscreen, sunburn medication.

The contents of a travel health kit should be tailored to a traveller's individual needs and health requirements, the length of stay and health risks prevalent in a given destination area. All medicines are to be bought in Poland or other developed countries because reports show that medications manufactured in the developing world, e.g. in South-East Asia, have little therapeutic value. When travelling to Asia or Africa, Polish globetrotters often buy local drugs for diarrheal diseases, febrile conditions or malaria chemoprophylaxis. Their prices are much lower but so is their quality and therapeutic value. Before taking any medication, you should always read the patient information leaflet containing the information on contraindications for use and possible drug interactions; travellers are recommended to note down the international names of the drugs they take regularly in case they lose their travel health kit or run out of the medications and we will have to buy substitutes [17].

\section{INSURANCE}

All recreational and professional divers travelling abroad are recommended to obtain a travel insurance including coverage for medical treatment and assistance. Insurance companies offer a variety of insurance plans ranging from basic to full coverage. You need to remember that basic plans offer little coverage and contain a number of exclusions, such as treatment of tropical diseases or treatment of injuries sustained from extreme sports. Travellers are also recommended to obtain an insurance including the coverage for medical evacuation and repatriation. If they are planning to engage in extreme sports, including diving, they should buy an insurance including coverage for rescue operation, as it is not normally covered by the accident insurance. Travelers should not forget about the luggage insurance as well because the loss of baggage may be financially painful for a traveller, especially if it is diving equipment. Divers travelling abroad should rather opt for an extended insurance coverage which covers the costs of specialist treatment (e.g. hyperbaric oxygen therapy), the costs of a rescue operation at sea and the liability insurance (personal injury or property damage). The cost of 
a policy may vary depending on a number of factors, e.g. recreational vs. technical diving, the diving depth (max. $30 \mathrm{~m}$ or deeper than $30 \mathrm{~m}$ with specialist diving equipment), the general health condition of a diver (chronic diseases). An insurance company may refuse to pay compensation if an incident occurred as a result of intoxication by alcohol or drugs [17].

\section{REFERENCES}

1. Lynch JH, Bove AA, Lynch JH, et al. Diving medicine: a review of current evidence. J Am Board Fam Med. 2009; 22(4): 399-407, doi: 10.3122/jabfm.2009.04.080099, indexed in Pubmed: 19587254.

2. Marienau KJ, Arguin PM. Diving medicine. In: Keystone JS, Freedman DO, Kozarsky PE, Connor BA, Nothdurft HD. ed. Travel medicine. 3rd edition. Saunders, Philadelphia 2013: 373-378.

3. Medical guidelines. Recreational Scuba Training Council. http:// www.wrstc.com/downloads/10\%20-\%20Medical\%20Guidelines. pdf (28 Sept 2017).

4. Harrison D, Lloyd-Smith R, Khazei A, et al. Controversies in the medical clearance of recreational scuba divers: updates on asthma, diabetes mellitus, coronary artery disease, and patent foramen ovale. Curr Sports Med Rep. 2005; 4(5): 275-281, doi: 10.1097/01.csmr.0000306222.19714.33, indexed in Pubmed: 16144586.

5. Dowse MS, Cridge C, Smerdon G. The use of drugs by UK recreational divers: prescribed and over-the-counter medications. Diving Hyperb Med. 2011; 41(1): 16-21, indexed in Pubmed: 21560980.

6. Leigh D. DAN discusses malaria and antimalarial drugs. Alert Diver Sept 2002. http://www.diversalertnetwork.org/medical/articles/ article.asp?articleid=80 (28 Sept 2017).

7. Denoble PJ, Caruso JL, Dear Gd, et al. Common causes of open-circuit recreational diving fatalities. Undersea Hyperb Med. 2008; 35(6): 393-406, indexed in Pubmed: 19175195.

8. British Thoracic Society Fitness to Dive Group, Subgroup of the British Thoracic Society Standards of Care Committee. British Thoracic Society guidelines on respiratory aspects of fitness for diving. Thorax. 2003; 58(1): 3-13, doi: 10.1136/thorax.58.1.3, indexed in Pubmed: 12511710.

9. Pollock NW, Uguccioni DM, Dear Gde L [Eds]. Diabetes and recreational diving: guidelines for the future. Proceedings of the UHMS/ DAN 2005 June 19 Workshop. Durham, NC: Divers, Alert Network; 2005. http://www.diversalertnetwork.org/news/download/SummaryGuidelines.pdf (28 Sept 2017).

10. Underwater physiology and diving disorders. In: U.S. Navy Diving Manual. Volume 1, Revision 6. http://www.supsalv.org/00c3_publications.asp (28 Sept 2017).

11. Taylor L. Diving physics. In: Bove AA, Davis JC JC. ed. Diving Medicine. 4th Edition. Saunders, Philadelphia 2004: 11-35.

12. Spira A. Diving and marine medicine review part I: diving physics and physiology. J Travel Med. 1999; 6(1): 32-44, doi: 10.1111/j.17088305.1999.tb00865.x, indexed in Pubmed: 10071371.

13. Bove AA, Moon RE. Patent foramen ovale - is it important to divers? In: Alert Diver, Sept/Oct 2004. http://diversalertnetwork.org/medi$\mathrm{cal} /$ articles/article.asp? articleid=70 (28 Sept 2017).

14. Vann RD, Lang MA [Eds]. Recreational Diving Fatalities. Proceedings of the Dives Alert Network 2010 April 8-10 Workshop. Durham, NC. http://d35gjurzz1vdcl. cloudfront.net/ftw-files/Fatalities_Proceedings.pdf (28 Sept 2017).
15. World Health Organization. Immunization, Vaccines and Biologicals. http://www.who.int/topics/immunization/diseases/en/ (20 Sept 2017).

16. Barnett ED. Yellow fever: epidemiology and prevention. Clin Infect Dis. 2007 ; 44(6): $850-856$, doi: $10.1086 / 511869$, indexed in Pubmed: 17304460.

17. Korzeniewski K. Medycyna podróży. PZWL, Warszawa 2016: 12-58.

18. Harrison LH, Trotter CL, Ramsay ME. Global epidemiology of meningococcal disease. Vaccine. 2009; 27 Suppl 2: B51-B63, doi: 10.1016/j.vaccine.2009.04.063, indexed in Pubmed: 19477562.

19. Health conditions for travellers to Saudi Arabia for the pilgrimage to Mecca (Hajj). Wkly Epidemiol Rec. 2009; 84(46): 477-480, indexed in Pubmed: 19928297.

20. Meningococcal vaccines: WHO position paper, November 2011. Wkly Epidemiol Rec. 2011; 86(47): 521-539, indexed in Pubmed: 22128384.

21. ProMED-mail. Poliomyelitis update: Global (Syria, Democratic Republic of the Congo). http://www.promedmail.org (22 Sept 2017).

22. Polio eradication. AccessScience., doi: 10.1036/1097-8542.yb130026.

23. Cholera, 2015. Wkly Epidemiol Rec. 2016; 91: 433-440.

24. ProMED-mail. Cholera, diarrhea and dysentery update: Asia (Yemen). http://www.promedmail.org (21 Sept 2017).

25. ProMED-mail. Cholera, diarrhea and dysentery update: America (Haiti). http://www.promedmail.org (16 Aug 2017).

26. Steinberg EB, Bishop R, Haber P, et al. Typhoid fever in travelers: who should be targeted for prevention? Clin Infect Dis. 2004; 39(2): 186-191, doi: 10.1086/421945, indexed in Pubmed: 15307027.

27. Guzman CA, Borsutzky S, Griot-Wenk M, et al. Vaccines against typhoid fever. Vaccine. 2006; 24(18): 3804-3811, doi: 10.1016/j. vaccine.2005.07.111, indexed in Pubmed: 16278037.

28. Askling HH, Rombo L, Andersson $\mathrm{Y}$, et al. Hepatitis A risk in travelers. J Travel Med. 2009; 16(4): 233-238, doi: 10.1111/j.17088305.2009.00307.x, indexed in Pubmed: 19674261.

29. Grabenstein JD. Hepatitis A vaccine. ImmunoFacts 2006: 175-185.

30. Keystone JS. Travel-related hepatitis B: risk factors and prevention using an accelerated vaccination schedule. Am J Med. 2005; 118 Suppl 10A: 63S-68S, doi: 10.1016/j.amjmed.2005.07.019, indexed in Pubmed: 16271544.

31. Jack AD, Hall AJ, Maine N, et al. What level of hepatitis B antibody is protective? J Infect Dis. 1999; 179(2): 489-492, doi: 10.1086/314578, indexed in Pubmed: 9878036.

32. Nothdurft HD, Zuckerman J, Stoffel M, et al. Accelerated vaccination schedules provide protection against hepatitis $A$ and $B$ in last-minute travelers. J Travel Med. 2004; 11(4): 260-261, doi: 10.2310/7060.2004.19013, indexed in Pubmed: 15541232.

33. Gautret $P$, Wilder-Smith A. Vaccination against tetanus, diphtheria, pertussis and poliomyelitis in adult travellers. Travel Med Infect Dis. 2010; 8(3): 155-160, doi: 10.1016/j.tmaid.2010.02.007, indexed in Pubmed: 20541135.

34. Rabies vaccines: WHO position paper. Wkly Epidemiol Rec. 2010; 85: 309-320.

35. Halstead SB, Thomas SJ. Japanese encephalitis: new options for active immunization. Clin Infect Dis. 2010; 50(8): 1155-1164, doi: 10.1086/651271, indexed in Pubmed: 20218889.

36. Dubischar-Kastner K, Kaltenboeck A, Klingler A, et al. Safety analysis of a Vero-cell culture derived Japanese encephalitis vaccine, IXIARO (IC51), in 6 months of follow-up. Vaccine. 2010; 28(39): 6463-6469, doi: 10.1016/j.vaccine.2010.07.040, indexed in Pubmed: 20673824.

37. Brunette GW. Yellow Book 2018. Health Information for International Travel. Oxford University Press, New York 2017. 